\title{
Inventario y Examen de las Traducciones Literarias en América
}

América fue siempre un campo florecido de altas expresiones en materia de traducciones literarias. En este continente han surgido muchos de los más valiosos traductores que se han manifestado en lengua castellana, pero su nombradía en cuanto traductores ha sufrido postergación al exaltarse otras facetas de su obra. La crítica o el comentario ha reparado poco en esa labor humilde pero trascendente y en contraste ha dado relieve intenso a otras expresiones de pasajero o temporal suceso.

Un espíritu avisado como el de Menéndez y Pelayo advertía, en una obra juvenil de hace más de 80 años, la singular importancia del estudio de las traducciones y sus autores, y escribía los cuatro volúmenes de su Biblioteca de Traductores Españoles ${ }^{1}$. Alli estuvieron presentes, en su recuento, preclatos nombres americanos como los centroamericanos José Batres Montúfar e Irisarri, el mexicano José J. Pesado, el colombiano Pombo y los peruanos Sancho Bravo de Lagunas, José Joaquín de Olmedo, Bernardino Ruiz, José Manuel Valdez y Juan de Arona. Su interés perseguía fundamentalmente a los autores de versiones de clásicos latinos, sin reparar todavía en la muy insigne obra de los traductores de las grandes figuras de las literaturas europeas modernas. Para aliviar a Menéndez y Pelayo del cargo de omisión o desdén por esos esforzados reveladores de la producción moderna, habría que señalar que justamen.

1 M. Menḱndez y Pelayo, Bibliotera de Traductores Españoles, Madrid, Consejo Superior de Investigaciones Científicas, 1953, 4 vols. 
te en el último siglo es cuando se ha desenvuelto el ejercicio donoso del verter la esencia creadora foránea en nuestra lengua y que en esa empresa delicada y exquisita han ocupado, dentro del mundo hispánico, lugar preferente los autores americanos. Cierto descuido prevaleciente en América en cultivar las investigaciones comparatistas ha determinado un tanto el retraimiento en reconocer la singular prestancia de los grandes autores americanos que han cultivado con honor y eficacia el arte de traducir, a quienes sólo lateralmente se les reconoce el mérito de tal empeño.2 Tampoco las versiones mismas han sido estudiadas en su carácter de instrumentos de difusión y vinculación literaria, de portadoras pre. claras de los elementos de transculturación producida de Europa a América y como puntales esenciales de todo ese caudal de estudio que entrañan las llamadas influencias literarias. Sobre los influjos literarios en autores americanos o en movimientos literarios mucho se ha escrito, en verdad, dando amplio campo a la improvisación o la apreciación subjeti. va, pero poco se ha tratado de esa materia con solera en investigaciones cuidadosas y sistemáticas. Se ha dado libre curso a la imaginación e inventiva de los comentaristas y críticas pero muy poco se ha sustentado en trabajos específicos de rastreo y análisis comparativo. Ello conduce a pensar en la necesidad de emprender en América hispano parlante un estudio integral de esas traducciones con un método adecuado como el que brinda la investigación comparatista. Debiéramos tener presente la afirmación del maestro Paul Van Tieghem cuando dice: "El estudio de las traducciones es el trabajo preliminar indispensable de la mayor parte de los trabajos de literatura comparada". 3 En pocas partes del globo adquiere mayor validez este aserto que en nuestra América.

Una tradición de eximios traductores exorna las letras de este continente. Sus méritos justifican la empresa de sacarlos del olvido y el desconocimiento en que se mantiene su obra de insignes traductores. Ya han padecido la suerte de los ignorados. Esto parece un signo adverso en los que generosamente han depuesto su soberbia de creadores y entregado su fruto para adornar la fama ajena. No cabe en la actividad literaria más humilde generosidad y renunciamiento más ejemplar, que los del traductor, contando con que son pocos los que suelen apreciar y valorar tan preciosa disposición y sabiduría literaria que supone la empresa de traducir. Resultan incalculables las nuevas perspectivas que

2 Debemos señalar, como excepción, un ensayo bibliográfico de José Toribio Medina, Biblioteca de Traductores, Santiago de Chile, 1923.

3 Paul Van Tieghem, La Littérature comparée, París, Lib. A. Colin, 1951. 
abre un estudio analítico semejante, no solamente para la comprensión de los autores sino también para la explicación de los fenómenos litera. rios múltiples en que el traductor es actor dinámico. El ejercicio mismo de traducir deja huella formativa profunda en el que realiza las versiones y éstas, al incidir sobre la realidad espiritual de los demás, genera imprevisibles resonancias en el mundo de la cultura de su momento o de su región.

España trajo a América la inquietud por el arte de traducir desde los mismos albores de la conquista hispánica. En Lima, Cuzco y Quito circularon por esos años del XVI, copias manuscritas de la donosa versión del Cantar de los cantares al romance que compuso Fray Luis de León, de aquella traducción clandestina que contra la prohibición inquisitorial de verter en lengua vulgar los textos bíblicos, constituyó cabeza de proceso para su enjuiciamiento y prisión por mandato del Santo Oficio. La inquietud renacentista imperante en España había inducido al insigne maestro salmantino a intentar una versión fiel al espíritu pero libre en la letra del texto del Cantar. Aquello significaba una reacción detonante contra la ortodoxia literaria, uncida hasta entonces al yugo de las tra. ducciones literales. El espiritu medieval se había afirmado en el culto de la letra y sus traductores desvanecían las esencias artísticas en su empeño de trasponer palabra por palabra. Sin quererlo o sin saberlo, incurrían inconscientes en la traición del espítitu. Desde el siglo xvi los tra. ductores adoptan otra actitud: la de ser fieles al espíritu aun con alteración de la letra pero sin su detrimento. La sensibilidad renacentista perseguía a través de sus traductores reconstruir en la lengua el sentido pro. fundo de la original, tan disminuido y deteriorado en sus esencias por los anteriores traductores literales. Si consideramos a Fray Luis como representativo de esa actitud renacentista, podríamos decir que con él se transporta al Nuevo Mundo la nueva concepción del traductor moderno y que en ella viene ínsita la repulsa del fanatismo tradicional. Como bajo una nueva advocación, comienza a prosperar en América el criterio re. novador, con el mismo aliento que anima a los traductores españoles coetáneos. Bajo esa tónica liberal y renacentista - librismo en vez de li. teralismo, el espíritu antes que la letra el Inca Garcilaso de la Vega, en I590, se inicia en las letras con una donosa versión de los Díalogos de Amor de León El Hebreo, la tercera y mejor traducción del toscano a la lengua romance de ese famoso libro platonizante. Rival de Garcilaso In. ca, por la misma época, pudo serlo en este menester de traslados, el humanista mexicano Francisco Cervantes de Salazar, insigne introductor de 
Luis Vives en nuestra cultura colonial. Con ellos y con otros más, se afirma en América la nueva técnica traductora que en España aún encon. traba la resistencia u oposición del tradicionalismo preceptista y la censura eclesiástica tratándose de los textos bíblicos. Ya desde 1580 hacen buena escuela de traductores en Lima y otras ciudades del Perú, Diego Dávalos y Figueroa desde su Academia Antártica, con Enrique Garcés y otros integrantes de dicha entidad. Petrarca y otros poetas itálicos menores ocupan el centro del interés de los traductores en ese momento. Más que lo bíblico o lo latino, despierta entonces la moda de conocer expresiones de literaturas románticas modernas como la italiana o la portuguesa. Del toscano vierte Garcés íntegramente a Petratca y otros poetas del Trescientos, e igualmente Dávalos comparte esta predilección por las letras de Italia. Garcés vierte seguidamente Los Lusiad'as de Luis de Camoens en su texto completo, como producto de largos años de afanes intelectuales en varias ciudades mincras del Perú. Un poco más adelante, en los comienzos del xvir, Diego Mexía de Fernangil publica en su Parnaso Antártico, una versión suya muy cuidada y también com. pleta de las epístolas heroicas de Ovidio, notable y duradera empresa muy apreciada hasta hoy, emprendida y realizada en el transcurso de un memorable y tormentoso viaje entre el Perú y México, obra concluida en tierra azteca y pulida en peruanas latitudes, que hermana el interés humanista que desde esa lejana época estaba despietto en los hombres cultos del Perú y de México, apenas a los 50 años de las respectivas conquistas y cuando estaba recién asentado el dominio español en esas tierras. Tanto Garcés como Mexía aprovechaban los ocios de viajeros o esperas imperiosas de su práctica actividad de mineros técnicos, en esas expansiones de verter escritores clásicos o modernos de su predilección. No desperdiciaron el tiempo libre, como hombres cultos que eran, y encontraron solaz espiritual en perfilar sus cuidadosas taducciones, im. pregnadas de ese nuevo espíritu renacentista que los llevó a mantener el "espiritu" del escritor traducido, aunque la "letra" sufriera trastocamiento.

El interés por los poetas italianos como Dante, Petrarca, Ariosto y Tasso se revela en las versiones constantes en toda América culta dentro del siglo siguiente, el xvII. En el Setecientos se destacan sobre la parte austral del continente insignes figuras de traductores del latín, del italiano y del francés, sobre todo, pues lo galo empieza ya a encender el entusiasmo de los estudiosos. Participan de esa actitud Pedro de Peralta y Pablo de Olavide. A la Biblia y a los clásicos latinos se suman los auto. 
res modernos y heterodoxos como Voltaire. En el norte, el padre Francisco Xavier Alegre, traductor de Boileau y de la Iliada de Homero, señala en México una inquietud semejante, de que también participan los clérigos Agustín Castro (intérprete de Horacio y Virgilio, Milton y Os. sian) y Anastasio de Ochoa, traductor de Ovidio, Racine y Boileau. Las versiones de los Salmos de David debidas a la pluma del peruano Olavide señalan nuevo rumbo a los traductores bíblicos castellanos que entonces se apartaban, vueltos al enclaustramiento tradicional, de las enseñanzas, admirables per'o peligrosas de Fray Luis de León, y se uncían sumisos a los preceptos neo-clásicos.

Sin duda la tradición renacentista de los traductores de alto vuelo, del tipo de Fray Luis de León y Garcilaso de la Vega Inca, había decaído un tanto en la época del barroco americano, cuyas figuras representativas son Peralta en el Perú y Sigüenza y Góngora en México, para quienes la traducción resulta mero ejercicio y fraseo, sin gran aliento creador. No obstante, Peralta, al traducir a Corneille, revela su inclinación a una técnica más liberal que le permite traducir con soltura y libertad a los franceses. Pero aún más se aleja de esa fidelidad al texto literal, el espíritu superior y revolucionatio (en sus mejores tiempos) de Olavide. Aunque su traducción de los Salmos corresponde a la época de la palinodia ideológica, no puede sustraerse su empresa del aliento renovador y liberal de su juventud y de su inquieta madurez cuando no era todavía un "filósofo desengañado". Mal de su grado, hasta sus últimos años, y a pesar de su contrición tardía, Olavide continuó siendo un hombre de la Ilus. tración y, pese al contenido y propósito místico de su versión de los Salmos, su método y sistema de traslado acusa un sentido de libre interpretación, muy contrario a su intención manifiesta. Ello demuestra que ni aun con esfuerzo el hombre de ideas puede sustraerse a la tónica y al sino de su época.

Al rayar el siglo xIx, un larvado romanticismo, ingénito de América y aún no aprendido de Europa, empieza a latir en todas las regiones del Nuevo Mundo. He revelado en otras páginas a Hipólito Unánue, médico y humanista, como precursor del romanticismo peruano, anterior a Melgar, tenido antes como la más prematura expresión de esta tendencia. Los hombres de la Ilustración fueron portadores de una nueva inquietud universalista que, a la par, nutría su curiosidad en la contemplación de la taturaleza americana y en la captación de las expresiones culturales de otros ámbitos europeos distintos de España o Italia. Empieza a contar 
y valer para ellos la bibliografía inglesa, norteamericana, germana y francesa, de nuevo cuño. Pero la inquietud "iluminista" se afirmaba en un fondo clásico tradicional que en mayor proporción venía del XVI clásico y renacentista antes que del xviII neoclásico, académico y aristocratizante.

Esa solera clásica y esa inquietud romántica coexisten en los traduc. tores americanos de comienzos del XIx. Los hombres ilustres, coincidentes en la inquietud, son Andrés Bello (178r-1865) en Venezuela, Mariano Melgar (I79r-1815) en el Perú y José Joaquín Pesado (I8or. 1860) en México. Y habría que agregar con igual título los nombres de José María de Heredia (1803-1839) en Cuba y José Joaquín de Ol. medo (1780-1847) que produjo su obra de traductor eximio entre Lima, Guayaquil y Londres, y a Domingo Navas Spínola, traductor venezolano de Horacio. Para ellos, la traducción fue, de un lado, ejercicio formativo a la sombra de los autores clásicos $\mathrm{y}$, de otro lado, fuente auténtica de inspiración. Cuando Bello traduce a los italianos como Boyardo y Tasso, o a los latinos como Horacio, Virgilio, Plauto y Tíbulo mantiene la misma fidelidad al "espíritu" de las obras, como cuando Melgar vierte Remedios de Amor de Ovidio o cuando J. J. Pesado traslada a Teócrito y Horacio, o Heredia adolescente a Virgilio, u Olmedo o Navas Spínola a Horacio. Pero cuando más logrado y maduro, Bello traslada a los modernos como Byron, Delille, Lamartine y Hugo, se muestra su actitud romántica declarada, haciendo por ejemplo de "La Oración por todos" de Víctor Hugo, una verdadera obra de concepción original y de forma acogedora de una auténtica y personal creación, como recientemente ha demostrado Eduardo Crema. La libérrima orientación romántica del arte de traducir se muestra igualmente en Olmedo al traducir el Ensayo sobre el bombre de Pope, o en Pesado al verter "La memoria de los muertos" de Lamartine, o en Heredia al trasladar el Saúl de Alfieri o los poemas de André Chenier o, finalmente, en el perunao-chileno Juan Egaña al elaborar su versión de Metastasio. Semejante actitud habría acusado Melgar de haber vivido más años, trasponiendo la edad de adolescencia en que imperaban todavía en su formación las enseñanzas clasicistas del Seminario de Arequipa. Esa generación de la época de transición de la Colonia a la República, demuestra la doble actitud espiritual proveniente de aquello en que fueron enseñados y de aquello que la vida les propuso como destino y acción. Surgen como traductores "literales" pero se desenvuelven en violenta evolución y desembocan en las versiones "libres", en cuanto adentran en la atmósfera romántica de los años que les toca vivir. 
La afirmación del romanticismo como escuela, a mediados del xIx, revela una legión de grandes y sensitivos traductores en cada país de Hispanoamérica, que trasladan y aclimatan las inquietudes parejas advertidas en paises europeos. Un breve recuento nos da la medida del fenómeno y de su alta calidad. En México lucen las versiones de José Gó. mez de la Cortina, Fray Servando Teresa de Mier y el obispo Montes de Oca. Alternan en sus predilecciones los antiguos clásicos como Horacio y Virgilio, con los recientes románticos como Chateaubriand, cuya Atala traduce Simón Rodríguez, ${ }^{4}$ el maestro del Libertador, en el comienzo del primer decenio del siglo (r8or). Venezuela puede enorgullecerse de haber producido a talentosos traductores como este último y Juan B. Cal caño, Arístides Rojas, Juan Vicente González, Domingo Navas Spínola (de Racine) y Juan Antonio Pérez Bonalde. Juan Vicente González tradujo en su Revista literaria de 1865,25 de los 34 Cantos del Infiemo de la Comeldia de Dante Alighieri. En una nota advertía que "sólo Dante, aunque imitado desde el siglo xIV y $\mathrm{xv}$, no ha obtenido, que sepamos, los honores de una traducción (al castellano). Años ha que emprendimos una, y vamos a publicar El Infierno... Nos hemos valido de casi todos los comentadores, desde Benvenuto de Rambaldi y Boccacio hasta Foscolo y Costa. Quizá repruebe alguno (añade celosamente González) que hayamos preferido traducir literalmente al gran poeta toscano, conservando sus giros, la forma de sus pensamientos, a veces sus italianismos y reteniendo, cuanto ha sido posible, el sabor de su estilo y lenguaje. Pero la elegancia nos parece inoportuna; y la paráfrasis no es otra cosa, en el estilo, que la trivialidad y el anacronismo". En cuanto a la primacía del intento, decía bien González, pues no se había publicado aún en España la versión completa por el peruano-hispano don Juan de la Pezuela (I879) ni tampoco la del argentino Bartolomé Mitre (I897) y en cuanto a la reprobación que predice por su intento de traducir literalmente, hay también acierto pues ya era esa una desusada forma de traducir, en pleno hervor del romanticismo.

A Pérez Bonalde (desde I877) se deben las mejores versiones de Heine y Poe en lengua castellana, no siendo menos valiosas las de Heine, Leopardi y Foscolo por Juan Bautista Calcaño y las del Viaje de Alejandro de Humboldt y de Rerum Naiura de Lucrecio (1892) por el múlti-

4 Esta versión fue antes atribuida al mexicano Fray Servando Teresa de Mier, pero la paternidad ha sido fijada por Pedro Garcés en reciente estudio donde hace iusticia a su verdadero autor, Simón Rodríguez. 
ple Lisandro Alvarado, filólogo y lingüista esclarecido. Es significativo además que la nombradia de Pérez Bonalde se debe casi exclusivamente a su labor de traductor.

En Venezuela no podemos dejar de mencionar a Rafael María Ba, ralt, autor de versiones de Parny, Vicenzo Monti, José Nicolini y sobre todo, de Dante Gabriel Rosetti, el apóstol del pre-rafaelismo inglés.

En el Perú hasta cuatro grandes figuras del romanticismo, como Ricardo Palma, Manuel González Prada, Pedro Paz Soldán y Unánue (Juan de Arona) y Clemente Althaus revelan con extraordinaria oportunidad y sentido interpretativo a casi desconocidos valores de la poesía inglesa, alemana e italiana, y gracias a ellos se incorporan al conocimiento general los nombres de Goethe, Schiller, Heine, Thomas Moore, Shelley y Leopardi, entre muchos otros ingleses, germanos, franceses e italianos. Omitimos la referencia a otros traductores peruanos de apreciable valía que, in extenso, tratamos en recientes volúmenes; ${ }^{5}$ sólo queremos aludir a José Arnaldo Márquez que, con Marcelino Menéndez y Pelayo como cotraductor, vertió en Barcelona, casi la obra completa de Shakespeare, en memorable empresa.

En Cuba los traductores románticos hicieron legión. José Martí, poeta de la acción y del ideal, apóstol de la independencia y paradigma en el verso y en la prosa de América, realizó felices versiones de Hugo y de Heine. Con dicha insigne figura de las letras continentales se vinculan, en esta actividad de finos traductores, José María de Heredia, Rafael María Mendive y Rafael María Merchán, Antonio y Francisco Sellén, quienes, en los ocios del destierro, dieron a conocer en castellano la lírica de Goethe y Heine, Byron y Moore, Hugo y Lamartine, Longfellow y Whitman, entre muchos más.

Chile dio igualmente un importante aporte con Salvador Sanfuentes (traductor de la Ifigenia de Racine a los 17 años), José Victorino Lastarria, y Eugenio Orrego Vicuña, cuidadoso traductor de Shakespeare, autor isabelino al que, uniformemente en todas partes del continente, sólo se conoce con el surgimiento del romanticismo. A Guillermo y Manuel An. tonio Matta se debe el traslado de obras integras de Heine, Schiller y

5 Estuardo Núñez, Autores germanos en el Perí (Lima, Min. de Educación Pública, 1953), Autores ingleses en el Perú (Lima, Min. de Educación Pública, 1957), Nuevos Estudios Germanos (Lima, 1957) y Nuevos Estudios Ingleses (Lima, 1958). 
Goethe. (El Fausto, I858). El magisterio del venezolano Andrés Be. llo en Chile tiene una faceta más en la labor traductora que continuó en sus últimos años, vertiendo (entre 1830 y 1840 ) algunas piezas como Teresa de Alejandro Dumas, Los rivales de Richard Brinsley Sheridan, una comedia de Moliére y algún fragmento de Dickens. Martín José Lira ( 1858 ) traduce El Salmo de vida de Longfellow y Carlos Morla Vicuña y José T. Medina (1874) su Evangelina.

En México se armoniza el aliento humanístico de grandes figuras de traductores que surgen desde el siglo xvi como Cervantes de Sala. zar, con la emoción romántica de los traductores del romanticismo como José Roa Bárcena, traductores de los grandes poetas alemanes modernos. Los empeños clasicistas son considerables en las versiones del padre Francisio Xavier Alegre, quien vierte la lliada en forma un tanto virgiliana y pegada a la tónica clásica latina pero sin color homérico, hasta Alfonso Reyes en nuestros días, desde Leopoldo Ayala, autor de $E l$ Virgilio mexicano que es obra ejemplar, hasta las traducciones de Horacio (1905) y las obras completas de Virgilio (1907-1913) por el religioso Joaquín Arcadio Pagaza (1859-1918) y las versiones horacianas excelentes del contemporáneo padre Alfonso Méndez Plancarte.

Entre los mexicanos, debemos una necesaria mención de Francisco A. de Icaza (1863-r945) que a más de glosador crítico y erudito de los clásicos españoles, se caracterizó como autor de versiones poéticas del Hebbel, Nietzsche, Dehmel y Turguienev con gran dominio de la lengua alemana.

A semejanza del mexicano Ayala, el gran poeta romántico colombiano Rafael Pombo, planeaba un Horacio bogotano, a base de sus ex. quisitas versiones confeccionadas (entre 1879 y r883) en prueba de aprecio a Marcelino Menéndez y Pelayo, a raíz de la aparición de su Horacio en España (1876). Pombo incrementó la contribución de América a la glotia de Horacio, que le había sido comunicada y proporcionada al crítico español por un gran cultor de las tradiciones clásicas en Colombia que fue don Miguel Antonio Caro. Pero Pombo no radicó su sabia dedicación sólo a la poesía latina, sino que ensayó y desarrolló antes, durante su larga residencia en los Estados Unidos, su talento interpretativo con los poetas modernos. "Así como Caro no dejó de ser clásico ni traduciendo a Lamartine, Pompo no perdió su genia. lidad romántica ni interpretando a Horacio", dice Antonio Gómez Restrepo. En efecto, el propio Pombo afirma que trató de verter lite- 
ralmente a Horacio, "siempre que el castellano y el metro to consintiesen; rompiendo con cierta etiqueta de lenguaje que vione de siglos atrás privándonos en ocasiones de expresarnos con la fuerza y verdad que admite nuestro idioma". Era esta una teoría muy moderna y romántica del arte de traducir, válida para toda una generación inquieta $y$ ejemplar en revelarnos en América las muestras más altas de la creación poética del Occidente. El mismo Miguel Antonio Caro, feliz colaborador de Menéndez y Pelayo, se destaca también como traductor de Virgilio (Eneida y Geórgicas) y Horacio (Odas) y otros modernos. Su obra excede en este aspecto, en volumen, a la obra de Pombo, pero no lo superó en su calidad artística ejemplar. Otro testimonio complementario del culto horaciano en América se encuentra en las versiones de la totalidad de Odas que cuminó en Chile Francisco Vergara Barros.

Antonio Gómez Restrepo no se limitó a enjuiciar a eximios traductores colombianos como Caro y Pombo en ensayo inserto en la edición completa de las versiones del primero, ${ }^{6}$ sino que analizó la obra traductora del argentino Bartolomé Mitre, escritor e historiador de noble empeño, y discutido traductor de La Divina Comeldia de Dante y de las obras integras de Horacio, el Ruy Blas de Victor Hugo y varias poesías de Byron y Longfellow. Gómez Restrepo pone en parangón la obra de Pombo con la de Mitre, resaltando cómo Mitre hizo de Horacio traducción literal, en calco del texto latino. En tanto, Pombo trató de mantener - con audacia y talento- el espíritu y el sentido del original pero dentro de la receptora sensibilidad de un moderno. "Procuraba Pombo, dice Gómez Restrepo, conservar el rasgo gráfico, la expresión pintoresca, en lo cual procedió con acierto indudable, pues ésta era una de las notas características del lirismo horaciano, como explicó sabiamente Caro, anticipándose a modernos humanistas, verbigracia a Reinach, el cual ha dicho que Horacio, en sus odas, es el Teófilo Gautier de los romanos". Y agregaba Gómez Restrepo precisando aún más su crítica de la traducción horaciana de Mitre, la cual puede valer también para su versión de la Comedia de Dante Alighieri: "es literal, pero infiel en lo más: sustancial, en lo que constituye el alma de la poesía, la cual se ha escapado como un perfume sutil de un pomo entreabierto, sin acertar a darnos expresión artística, la callida junctura","

6 Traducciones poéticas de Rafael Pombo, Edición de Antonio Gómez Restrepo, Bogotá, Imptenta Nacional, 1917.

7 Traducciones.... obra cit., prólogo de Antonio Gómez Restrepo. 
El nombre de Mitre evoca el de otros esforzados y disciplinados traductores argentinos de autores clásicos. El hispanoargentino Ventura de la Vega (1807-I865) tradujo del latín el primer libro de La Eneida en esfuerzo de prestancia y sensibilidad muy encomiables pero "sin sabor virgiliano" y en calidad y hondura muy inferiores a la realización de Miguel Antonio Caro, preclaro humanista. Ventura de la Vega estuvo más a tono cuando emprendió la versión de poetas franceses modernos y sobre todo de dramas románticos de Scribe, A. Duval, C. Delavigne, Victor Hugo, Bouchardy y otros no identificados.

La tradición virgiliana argentina se manifiesta igualmente en las traducciones de La Eneida, por Dalmacio Vélez Sarsfield, que al mismo tiempo fue notable jurista ${ }_{2}$ y Juan Cruz Varela. Hay que ver en ellas algo más que un simple y ejemplar "ejercicio de lengua". Domingo Faus. tino Sarmiento se encargó en el prólogo de exaltar estos esfuerzos en la edición conjunta de dichas obras. ${ }^{8}$ Vélez Sarsfield tradujo en prosa los Cantos I al VI, en tanto que Cruz Varela abarcó, en verso endecasílabo, los cuatro primetos cantos, pero de ellos sólo se ha conservado el libro I y parte del II. Sarmiento intenta un estudio comparativo de algunos pasajes de Vélez Sarsfield con las versiones del español Velasco y otras francesas e inglesas. Anota también Sarmiento que Vélez Sarsfield tuvo a la vista, además del de Velasco, los textos de Barthélemy, Dryden, Malherbe, Delille, Bondi, Villeneuve, Annibal Caro, Davison, Binet, lo cual demuestra su erudición de esta materia. De otro lado Juan Cruz Varela había traducido también varias Odas de Horacio, a más de obras de Racine y Alfieri. Su información de los latinos se demuestra en la carta que dirigió, en I836, a Bernardino Rivadavia "sobre la manera de traducir los poetas latinos y especialmente Virgilio", en donde comenta y critica ${ }_{2}$ con autoridad desusada en América, la versión francesa de Delille.

Entre los traductores argentinos de literatura moderna, es nombre precursor el de José Antonio Miralla, a comienzos del xIx, eximio y fogoso traductor de Gray, Byron y Hugo Foscolo y animador literario continental con acción decisiva en el Perú ${ }_{2}$ Ecuador, Cuba y México.

La traducción del culto arte de traducir que caracteriza la lite-

8 Virgilio, La Eneida en la República Argentzna, trad. de D. Vélez Sarsfield y J. Cruz Varela. Reseña de Domingo F. Sarmiento y Adolfo Saldías, Buenos Aires, F. Lajouane, Editor, 1888. 
ratura colombiana, tiene otros exponentes más recientes en el presente siglo. Guillermo Valencia, el gran parnasiano, ha continuado la ruta y seguido el ejemplo de Miguel Antonio Caro, Pombo, José Eusebio Caro, José Asunción Silva ${ }_{2}$ el propio Antonio Gómez Restrepo -traductor de 35 Cansos de Leopardi y compilador de las versiones de Pombo y de Ismael Enrique Arciniegas y el rastro altísimo de Víctor M. Londoño, José Joaquín Casas, Carlos Arturo Torres y Eduardo Castillo. Como todos ellos, su interés manifiesto incidió en los autores modernos europeos y así debemos a Valencia versiones exquisitas (descontando a Camoens) de Peter Altenberg, Stephan George, Hugo von Homannsthal, D'Annunzio, Machado de Assis, Wilde, y los eximios franceses Baudelaire, Verlaine, Flaubert, Mallarmé, Heredia y Maeterlinck. Tanto a Valencia, como a todos los traductores ya nombrados debe mucho la cultura literaria de América, enriquecida de ese modo con el flujo y la savia del aporte artístico europeo y universal.

No queda atrás el nuevo rumbo de la crítica en Venezuela que tan promisor empuje adquiere en los últimos años. Lo demuestran así las investigaciones en la historia de las ideas que ha emprendido recientemente García Bacca, las indagaciones sobre traductores de Eduardo Crema - y René L. F. Durand, los trabajos bibliográficos y críticos de Pedro Grases y Mariano Picón y ciertos trabajos preliminares de investigadores nuevos como R. Fernández Heres, de quien he leído hace poco un inventario de traductores clásicos, entre los cuales revela nombres antes poco conocidos en este menester humanístico del traslado de clásicos latinos, como los de José Luis Ramos, Luis Flegel, Irisarri, y las precla. ras figuras de Juan Vicente González y Cecilio Acosta. Hace poco hemos leído la excelente versión de $L_{a}$ joven Parca de Paul Valery por Alí Lameda.

En las letras ecuatorianas inicia un magisterio insigne de traductor José Joaquín de Olmedo, a quien dedico párrafos reveladores en un reciente libro sobre autores ingleses, el cual muestra asimismo el singular culto que despertaron poetas modernos como Byron en escritores ecuatorianos casi desconocidos como Vicente Emilio Molestina, y también la poetisa Angela Caamaño de Vivero. La tradición continúa en Gabriel García Moreno, traductor de los Salmos y en Julio Zaldumbide (18331887), autor de una versión del Lara de Byron y Los Sepulcros de Pindemonte, y en Simón Martínez Izquierdo, traductor de Longfellow.

En Bolivia dicha tradición es considerable. En el mismo citado 
libro mío, he revelado a Mercedes Belzu y José de Urcullu, que admiran a Byron y Gray respectivamente. El gran poeta boliviano Gregorio Reynolds tradujo el Edipo Rey de Sófocles, basándose en las versiones francesas de Laconte de Lisle y Paul Masqueray. Néstor Galindo (18301865) tradujo el Adiós de Chile Harold de Byron y otros poemas del mismo y de Victor Hugo y a otros poetas franceses del romanticismo. En la generación posterior se destacaron la recia figura de Franz Tamayo, traductor de Horacio y Anacreonte y Eduardo Díez de Medina, quien ha dejado un libro de versiones francesas con poemas de creadores de su predilección como Verlaine, Mallarmé y Geraldy, a más de otras inspiradas traducciones de Kipling, Bilac y Correa.

Gracias a sus traductores literarios, América fortalece su universalidad y logra mantenerse abierta y asimilante de las más varias inquietudes. Recepciona todas las corrientes literarias y afirma frente a su influjo una originalidad posteriormente revelada. En pleno siglo xIx, van a sobrevivir todavía traductores de clásica estirpe como el Obispo Montes de Oca en México o el peruano José Pérez de Vargas, pero el impulso general y la tónica nueva están dadas por los grandes poetas del romanticismo. La traducción no es ni lo fue nunca una actividad subalterna ni mediatizada. La cultivan nuestros grandes escritores con orgullosa prestancia y con vehemencia incontenible. Gracias a ellos, se incorpora al acervo de la cultura popular la obra literaria de los grandes espíritus europeos de todas las razas y religiones. Al lado de los itá. licos y franceses, se revelan autores ingleses y alemanes en libre y espléndida difusión. El fermento espiritual de la moderna literatura europea se hace firme en el espíritu americano y esa nueva inspiración de las corrientes literarias del siglo xIx conjuga con la desconocida savia de autores anteriores nunca o podo revelados.

En tiempos más recientes no ha decrecido la inquietud, pero es más laborioso seguir el rastro de la labor producida por la falta de monografías específicas sobre la materia. En México, el afán y la tarea humanística de Alfonso Reyes asedia ahora los poemas homéricos, lo cual parece ser actitud persistente en todos los siglos de la literatura mexicana. Otro insigne humanista de nuestra época, hace poco desaparecido, Alfonso Méndez Plancarte, ejemplar estudioso de Sor Juana y de Díaz Mirón, ha producido eximias versiones de Horacio que son, sin duda, por lo depuradas y cabalmente realizadas, superiores a las de Caro y Pombo, en un logrado ensayo de "versiones rítmicas". En otros países 
de Hispanoamérica, Mariano Brull (traductor de Paul Valery), León Felipe, Jorge Luis Borges, Octavio Barreda, Jorge Zalamea, Francisco Aguilera, Emilio Oribe, Luis Alberto Sánchez, Yolando Pino Saavedra, entre muchos más, mantienen la prestante trayectoria de la traducción literaria americana en alto nivel de calidad.

Pero esta selecta estirpe de producción literaria merece la sistemática valoración y el detenido estudio monográfico, y que sea revelada en su proyección espiritual y estética en todos los países de ascendencia hispánica, en donde este tipo de investigaciones se encuentra postergado. La crítica y el comentario analítico deben dirigirse mediante condigna atención y renovado interés hacia esta sugestiva faceta de la producción literaria americana. A ella venimos dedicando en el Perú empeñosa labor que abarca por el momento un ámbito nacional o colindante. Pero el estudio regional exige correlativo empeño en las áreas restantes. Así lo recomendó un acuerdo de las "Jornadas de la Lengua y Literatura Hispanoamericana" de Salamanca en 1953, en las que sostuvimos la ponencia respectiva. Para ello podremos contar dentro de poco con los fascísculos que van apareciendo del Repertorio Bibliográfico de la literatura bispanoumericana que se elabora, bajo dirección de Luis Alberto Sánchez, en las Universidades de San Marcos de Lima y de Santiago de Chile, en común y afanoso esfuerzo. Los resultados de una investigación acerca de los traductores y de las traducciones, supone paciente labor hurgadora sobre todo en papeles periódicos y revistas de indole literaria, más que en los escasos libros que existen sobre la materia, han de proporcionar insospechadas conclusiones en cuanto a las "fuentes" precisas de la producción literaria continental, derivando de ellas resultados preciosos relativos a la originalidad y voluntad de creación en nuestros más representativos escritores.

Estuardo NúÑez.

Universidad de San Marcos,

Lima $_{1}$ Perú. 